\title{
Ni(0)-catalyzed polycondensation of silafluorene: control over molecular weight and polymer growth mechanism
}

\author{
Makoto Tanabe, Shunsuke Iwase and Kohtaro Osakada* \\ Laboratory for Chemistry and Life Science, Institute of Innovative Research, \\ Tokyo Institute of Technology \\ 4259-R1-3 Nagatsuta, Midori-ku, Yokohama 226-8503, Japan \\ E-mail: kosakada@res.titech.ac.jp
}

Table of contents

Figure S1 Estimation of the molecular weight of poly-2 $\quad$ S2

Figure S2 GPC charts of the poly-2 and the plots of the relative S3

Figure S3 $\quad{ }^{1} \mathrm{H}$ NMR spectra of polymerization of 2 with removal of $\mathrm{H}_{2} \quad$ S4

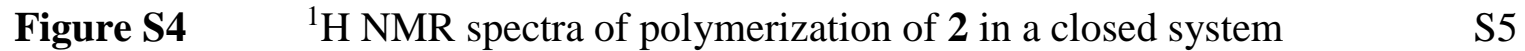

$\begin{array}{lll}\text { Figure S5 } & { }^{1} \mathrm{H} \text { NMR spectra of reaction of tetra-2 without } \mathrm{H}_{2} \text { gas } & \text { S6 }\end{array}$

Figure S6 $\quad{ }^{1} \mathrm{H}$ NMR spectra of reaction of tetra-2 under $\mathrm{H}_{2}$ atmosphere $\quad$ S7 


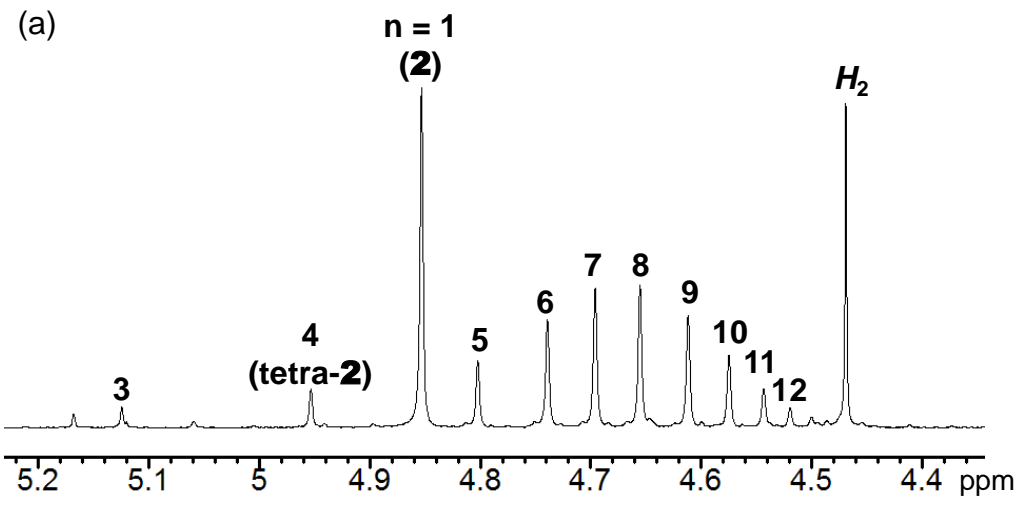

$$
\begin{aligned}
& \text { (b) } \\
& \boldsymbol{M}_{\mathrm{n}}=\frac{\left(\mathrm{X}_{3} \times \mathrm{I}_{3}\right)+\left(\mathrm{X}_{4} \times \mathrm{I}_{4}\right)+\cdots\left(\mathrm{X}_{\mathrm{n}} \times \mathrm{I}_{\mathrm{n}}\right)}{\mathbf{I}_{3}+\mathbf{I}_{4}+\cdots \mathbf{I}_{\mathrm{n}}}=\mathbf{2 2 5 0} \\
& \boldsymbol{M}_{\mathbf{w}}=\frac{\left.\left.\left.\left\{\left(\mathbf{X}_{3}\right)^{2} \times \mathbf{I}_{3}\right)\right\}+\left\{\left(\mathbf{X}_{4}\right)^{2} \times \mathbf{I}_{4}\right)\right\}+\cdots\left\{\left(\mathbf{X}_{\mathrm{n}}\right)^{2} \times \mathbf{I}_{\mathbf{n}}\right)\right\}}{\boldsymbol{M}_{\mathrm{n}} \times\left(\mathbf{I}_{3}+\mathbf{I}_{4}+\cdots \mathbf{I}_{\mathbf{n}}\right)}=\mathbf{2 4 6 0} \\
& M_{w} / M_{n}=1.09 \quad \mathrm{X}_{n}=\text { Molecular weight of Sin } \\
& \mathrm{I}_{n}=\text { Integration ratio of Sin }
\end{aligned}
$$

Figure S1. (a) ${ }^{1} \mathrm{H}$ NMR spectrum after the polymerization of 2 for $3 \mathrm{~h}$; signals were assigned according to the 2D DOSY spectrum. (b) The number-average molecular weight $\left(M_{\mathrm{n}}\right)$, weight-average molecular weight $\left(M_{\mathrm{w}}\right)$ and the polydispersity index $\left(M_{\mathrm{w}} / M_{\mathrm{n}}\right)$ were calculated from the integration ratio of the $\mathrm{Si}-\mathrm{H}$ peaks for tri-2 and dodeca-2. 
(a)

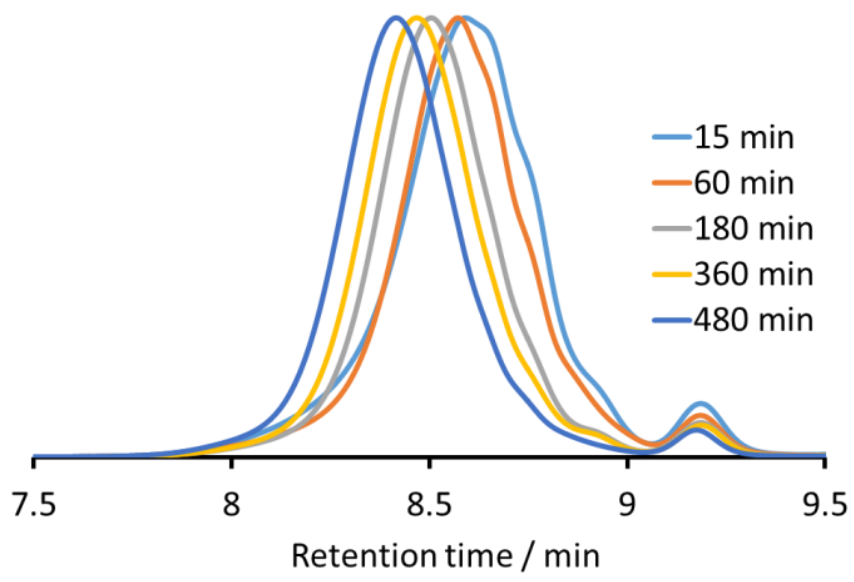

(b)

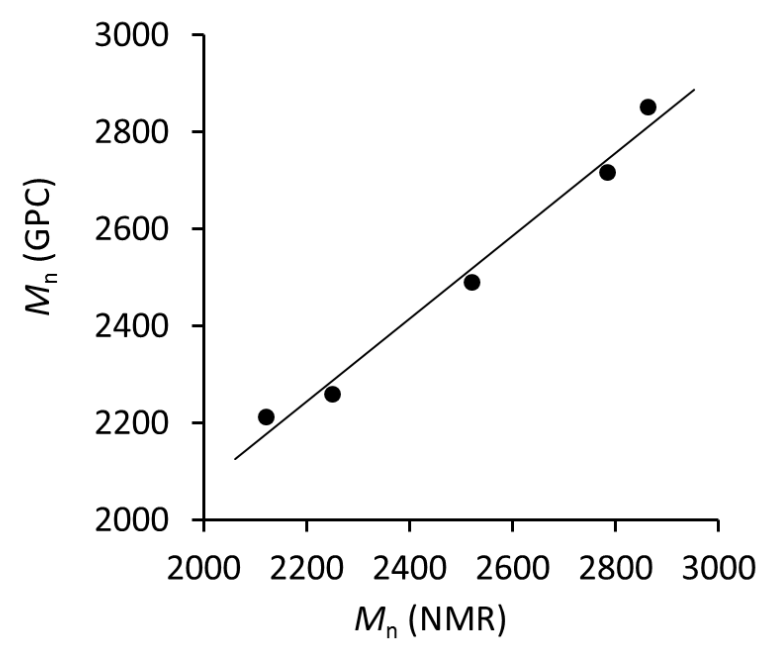

Figure S2. (a) Polymerization time-dependent GPC profiles of poly-2. (b) Correlation between the molecular weight of poly- 2 estimated on the basis of the ${ }^{1} \mathrm{H}$ NMR signals and GPC results. 

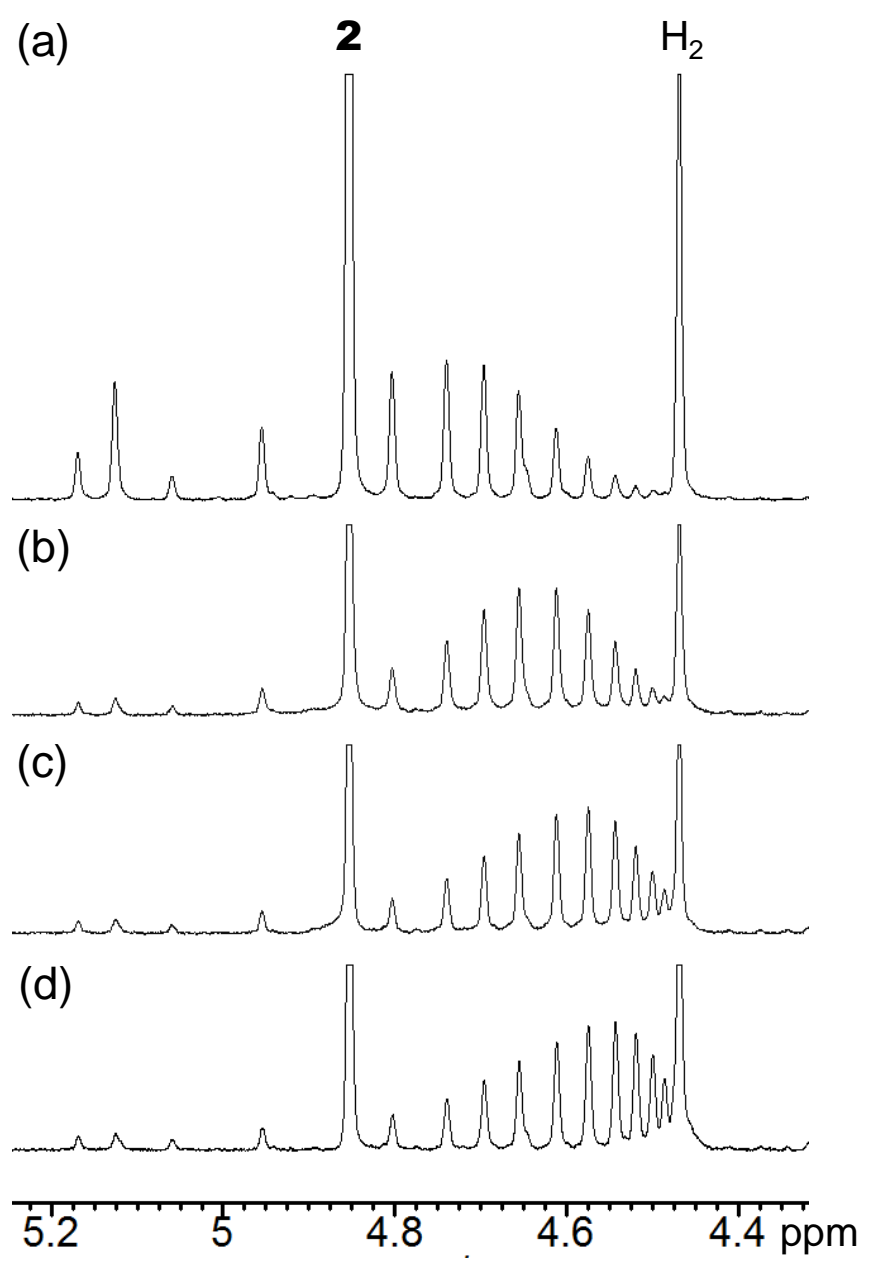

Figure S3. Monitoring the polymerization of 2 by ${ }^{1} \mathrm{H}$ NMR (closed system): after (a) 30 min, (b) $24 \mathrm{~h}$, (c) $48 \mathrm{~h}$ and (d) $72 \mathrm{~h}$. 

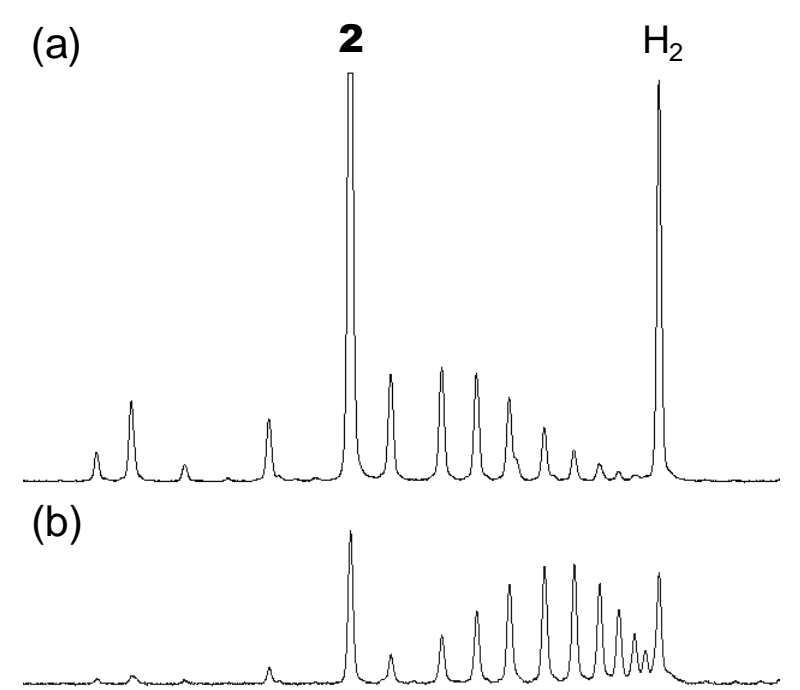

(c)
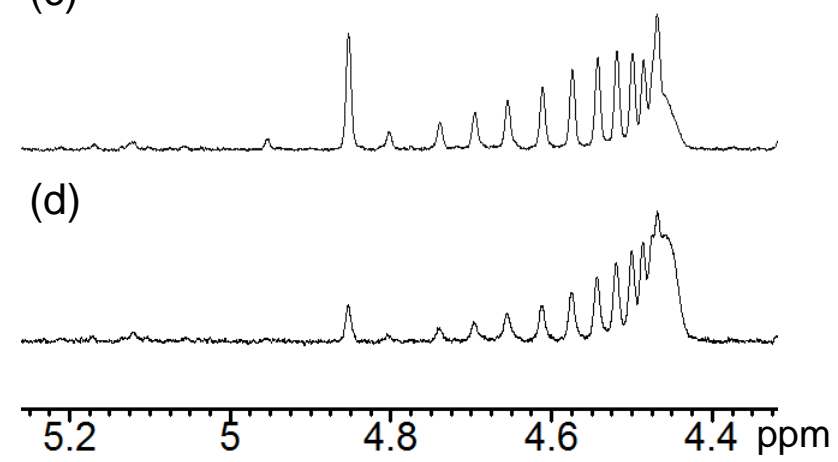

Figure S4. Monitoring the polymerization of 2 by ${ }^{1} \mathrm{H}$ NMR (closed system): (a) $30 \mathrm{~min}$, (b) $24 \mathrm{~h}$, (c) $48 \mathrm{~h}$ and (d) $72 \mathrm{~h}$ after adding the Ni catalyst to the reaction mixture. $\mathrm{H}_{2}$ evolved during the reaction was removed after every NMR measurement via freeze-pump-thaw cycles. 


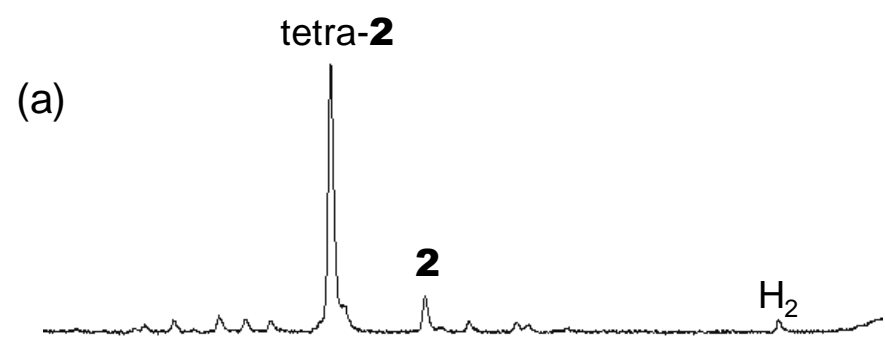

(b)

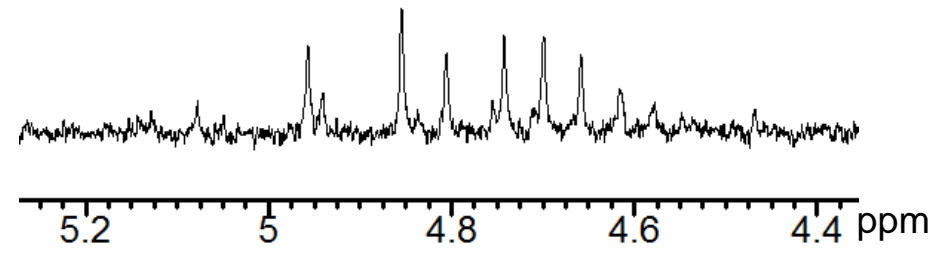

Figure S5. Monitoring the polymerization of tetra-2 by ${ }^{1} \mathrm{H}$ NMR (closed system): after (a) 8 $\mathrm{h}$ and (b) $96 \mathrm{~h}$. 


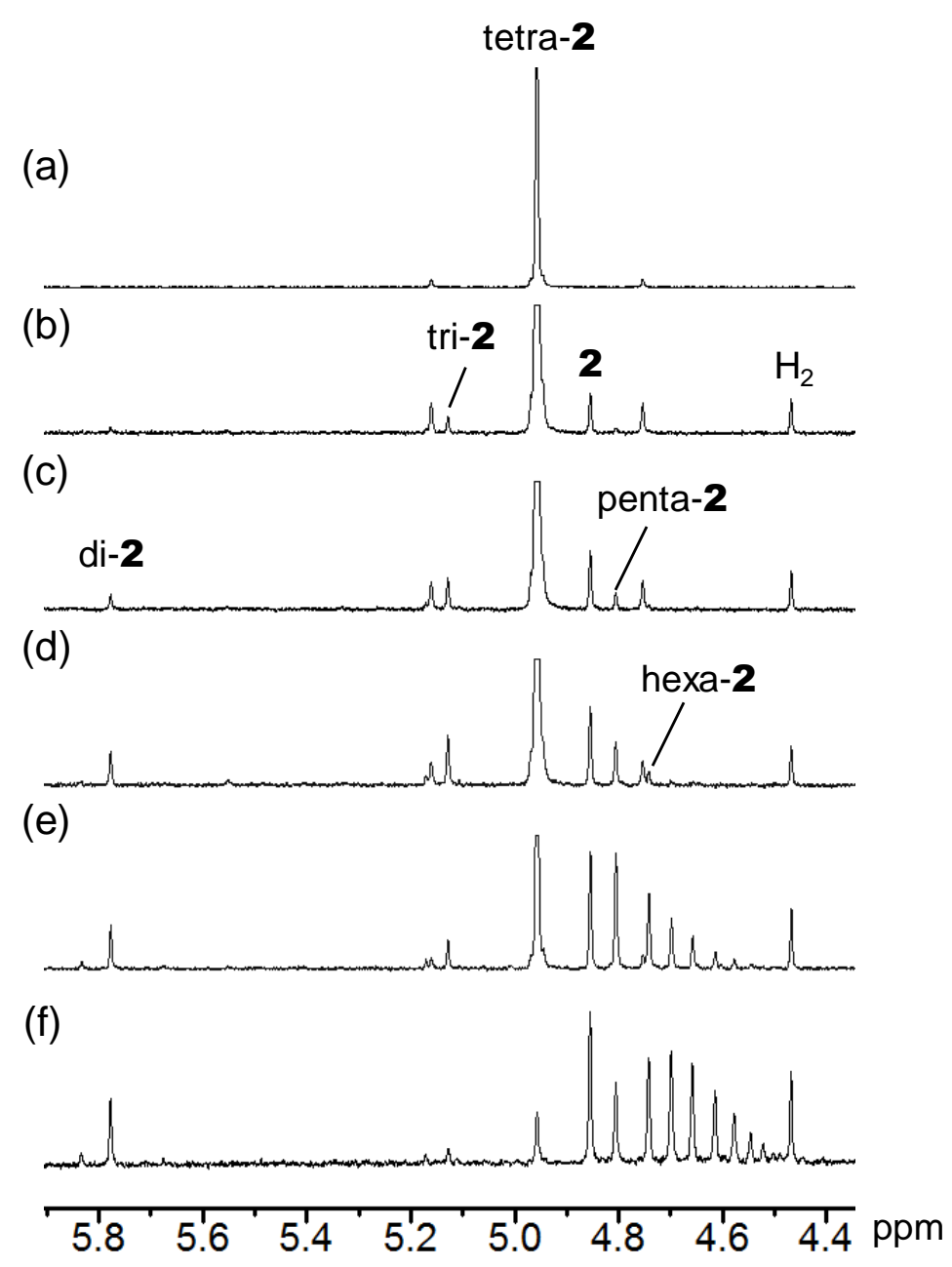

Figure S6. Monitoring the polymerization of tetra-2 by ${ }^{1} \mathrm{H}$ NMR (open system): (a) before adding the Ni catalyst, and (b) $10 \mathrm{~min}$, (c) $1 \mathrm{~h}$, (d) $3 \mathrm{~h}$, (e) $16 \mathrm{~h}$ and (f) $48 \mathrm{~h}$ after adding the catalyst. 